\title{
AN OPTIMAL HYDRODYNAMIC EFFECT
}

All too often manual toothbrushes result in back and forth scrubbing with too much pressure which can cause damage. The Curaprox Hydrosonic CHS 100 toothbrush ensures that teeth and gums are optimally cleaned in a soft and gentle way.

The Hydrosonic CHS 100 has three cleaning modes, a two minute timer and a 30 second jaw-quadrant timer, which together provide effective brushing, whatever your needs.

Hydrosonic CUREN bristles, unlike nylon, do not absorb water and therefore maintain their firmness for an optimal hydrodynamic effect. This guarantees deep cleaning in concealed niches between the teeth. The brush is designed to remove plaque without damaging the gums, making it more effective than a traditional brush.

Each Hydrosonic CHS 100 is supplied with free brush heads for life, a charger and travel case containing three interdental brushes and one Enzycal toothpaste $(15 \mathrm{ml})$.

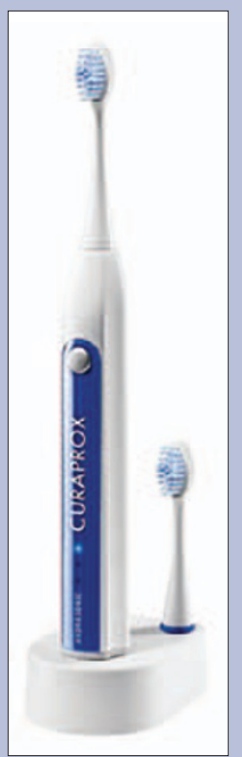
At the attractive price of $£ 74.95$, the Hydrosonic is a brush for life.

Reader response number $\mathbf{5 8}$

\section{RAPID RESIN CURING}

Now available from The Dental

Directory, the Ledmax Ultimate

Fast LED Curing Light is perfect for practices seeking to invest in a highpower curing light designed for rapid curing of resins and other adhesives.

The Ledmax Ultimate Fast LED

Curing Light is available in either corded (QCH350) or cordless (QCH330) versions, is fully autoclavable, and features high light intensity $\left(1,500 \mathrm{mw} / \mathrm{cm}^{2}\right)$ as standard. The product also comprises an integrated light meter with duo colour indicator, and comes complete with an image grade Multifiber Turbo Light Guide to maximise light intensity and hygiene.

Both corded and cordless models feature simple controls with audible signals for efficient mode selection, and can be set for 5, 10, 20 and 120 second

\section{STUDENT CLINICIAN AWARDS}

The BDA/DDU/Dentsply Student Clinician Awards programme supports international undergraduate study and focuses on original research.

This prestigious programme gives students a valuable opportunity to gain research experience and the continuous exposure limits for ease of use. Audible signal options include a totally silent mode, or a signal every five seconds.

Eye protection shield and no-glare cones are included as standard with the Ledmax Ultimate Fast LED Curing Light, along with curing depth tester apparatus. Reader response number 59

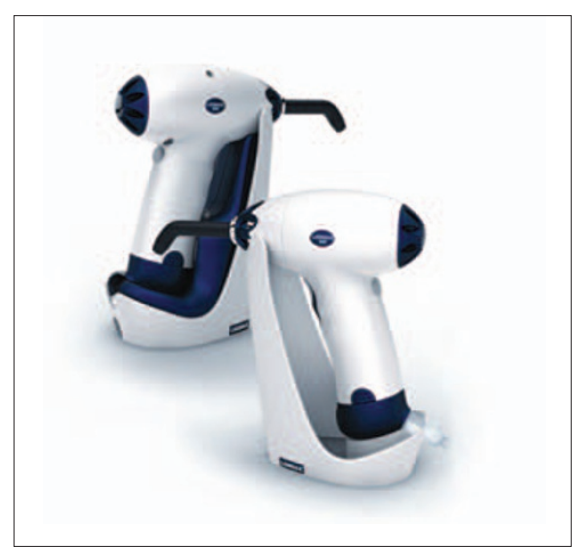

chance of a trip to San Francisco. In addition to this, the winner's school will receive a $£ 10,000$ research grant.

Now in its 35th year, the BDA/DDU/ Dentsply Student Clinician Programme Awards ceremony will be held at The Royal Horseguards Hotel in London on 3 February 2012.

Reader response number 60 